Mark Hünlich Gerd Hasenfuss

\section{Effects of the NO donor sodium nitroprusside on oxygen consumption and energetics in rabbit myocardium}

Abstract Nitric oxide (NO) has influence on various cellular functions. Little is known of the influence of NO on myocardial energetics. In the present study oxygen consumption and mechanical parameters of isometrically contracting rabbit papillary muscles $(1 \mathrm{~Hz}$ stimulation frequency) were investigated at varying interventions while maintaining physiological conditions $\left(37^{\circ} \mathrm{C} ; 2.5 \mathrm{mM} \mathrm{Ca}{ }^{2+}\right)$ to study the effects of NO on energetics. The NO donor sodium nitroprusside (SNP) showed a negative inotropic effect. SNP decreased the maximal force in normal rabbit muscle strips by $30 \%$, the force time integral (FTI) by $40 \%$ and the relaxation time by $20 \%$. In addition the oxygen consumption decreased by $60 \%$, a notably disproportional decrease compared to the mechanical parameters. Consequently, the economy as a ratio of FTI and oxygen consumption is significantly increased by SNP. In contrast the negative inotropic effect due to a reduction in extracellular Calcium $\left(\mathrm{Ca}^{2+}\right)$ from 2.5 to $1.25 \mathrm{mM}$ reduced FTI and oxygen consumption proportionally by $40 \%$ and did not change economy. The effect of NO on force and oxygen consumption could be reproduced by the application of the cyclic guanosine monophosphate (cGMP) analogue 8-bromo-cGMP. In summary, NO increased the economy of isometrically contracting papillary muscles. The improvement in contraction economy under NO seems to be mediated by cGMP as the secondary messenger and maybe due to alterations of the crossbridge cycle.

Key words energetics - NO - myocardium - oxygen consumption
M. Hünlich, MD $(\bowtie) \cdot$ G. Hasenfuss, MD Universitätsklinik Göttingen

Abteilung für Kardiologie

Robert-Koch-Straße 40

37099 Göttingen, Germany

Tel.: +49-551/396-371

Fax: +49-551/396-347

E-Mail: huenlich@med.uni-goettingen.de transmitters of the endocard or endothelium [41, 42]. $\mathrm{NO}$ and other substances which increase the intracellular cGMP level, decreased the systolic tension in single myocytes, muscle strips and isolated hearts. Simultaneously, single contraction parameters, especially contraction time, were also altered. The acceleration in relaxation time was the main reason for the significant shortening of the contraction time $[20,35$, 37, 42]. 
Both, basal and cytokine induced NO synthesis influence the effects of $\beta$-adrenergic stimulation. Several experiments have shown that the positive inotropic effect of isoprenaline was significantly decreased in the presence of NO [1, 39, 46, 47]. This effect is nearly eliminated by the inhibition of NO-synthases through L-NMMA.

The influence of NO on myocardial inotropic, chronotropic and dromotropic response seems to be biphasic [36]. Kojda et al. [15] observed that isolated ventricular rat myocytes exhibited a small, however significant positive inotropic reaction as well as an elevated isoprenaline effect under a small concentration of the NO-donor S-Nitroso-N-Acetyl Penicillamin (SNAP). In the same experiment higher doses of SNAP decreased maximal systolic tension.

The endocardium plays an important role in the regulation of the myocardial function by NO. Fort et al. [5] showed that the intraventricular infusion of SNP at any concentration into hearts without endocardium had no effect on maximal tension and relaxation time. However, if SNP was added to coronary arteries with endothelium, the left ventricular tension decreased and the relaxation time was shortened. Moreover, in papillary muscles isolated from pigs with the endocardium removed, SNP showed a positive inotropic outcome. These findings validate the influence of endocardium or respectively endothelium on the decrease in systolic tension and shortened relaxation time in myocardium.

The observed changes in muscle mechanics led to the supposition that NO may influence the oxygen consumption as well as energetics of myocardium. To identify the effects of $\mathrm{NO}$ on energetics we investigated the influence of the NO donor SNP on papillary muscle contractions and oxygen consumption. The effects of NO were compared with the effects of cGMP as well as with a change in extracellular $\mathrm{Ca}^{2+}$ concentration.

\section{Methods}

\section{Papillary muscle preparation}

Animal handling was reviewed and approved by the Animal Investigation Committee of the University of Goettingen. Right ventricular papillary muscles were gathered from New Zealand White rabbits $(2.2-2.8 \mathrm{~kg}$ body weight). Immediately after cardiectomy, the heart was removed and submerged in cold $\left(4^{\circ} \mathrm{C}\right)$ protective solution bubbled with $95 \% \mathrm{O}_{2}$ and $5 \% \mathrm{CO}_{2}$ (Carbogen). The solution contained $(\mathrm{mmol} / \mathrm{l}) \mathrm{Na}^{+}$ $152, \mathrm{~K}^{+} 3.6, \mathrm{Cl}^{-} 135, \mathrm{HCO}_{3}{ }^{-} 25, \mathrm{Mg}^{2+} 0.6, \mathrm{H}_{2} \mathrm{PO}_{4}^{-} 1.3$ $\mathrm{SO}_{4}{ }^{2-} 0.6 \mathrm{Ca}^{2+} 2.5$, glucose 11.2 and 2,3-butanedione monoxime (BDM) 30 along with $10 \mathrm{IU} / 1$ insulin
(Hoechst, Inc). All chemicals were purchased from Sigma (Sigma, Inc) unless otherwise indicated. This protective solution was shown to preserve myocardium during transportation and dissection and to be completely reversible after washout [24]. Ventricles were gently rinsed to clear remaining blood. Preparation of myocardium was performed in a dissection chamber filled with the protective solution. Right ventricular papillary muscles were abscised at the base from the ventricular wall. Only long, cylindrical muscles were used.

\section{Experimental protocol}

Papillary muscles were placed into the measurement apparatus (Muscle Research System, Scientific Instruments, Heidelberg, Germany) and clamped at both ends. The muscles were perfused with KrebsRinger solution (composition as above without BDM) bubbled with Carbogen and warmed to $37^{\circ} \mathrm{C}$. Hepes Buffer with a concentration of $5 \mathrm{mmol} / \mathrm{l}$ at a $\mathrm{pH}$ of 7.4 was used in addition to the Krebs solution during the SNP experiments. Isometric contraction was accomplished by stimulation with a $5 \mathrm{~ms}$ pulse applied endto-end at a voltage $25 \%$ above threshold and a frequency of $1 \mathrm{~Hz}$. After an equilibration period of $30 \mathrm{~min}$, muscles were stretched in $0.05 \mathrm{~mm}$ increments until additional stretch did not produce an increase in developed force. This length was taken as $l_{\text {max }}$. Mechanical parameters (twitch tension and timing parameters) and oxygen consumption were measured at steady state conditions. Dose-response experiments were performed with incremental doses of SNP and 8-bromo cGMP in each muscle preparation.

Isometric force was acquired digitally from the force transducer (KG4, Scientific Instruments). Twitch tension was defined as the active tension developed during the isometric twitch. Force-time integral was calculated as the area under the twitch force curve. At the end of each experiment muscle length and weight were measured. Cross-sectional area for normalization of force values was calculated as the ratio of blotted muscle weight to muscle length $\left(l_{\max }\right)$.

\section{Oxygen consumption}

The method used to measure oxygen consumption was described and validated previously [21]. Briefly, a miniature oxygen electrode continuously measured $\mathrm{PO}_{2}$ in the experimental chamber close to the muscle surface. The drop in $\mathrm{PO}_{2}$ at the probe tip was measured over $20 \mathrm{~s}$ and compared to precalculated theoretical profiles to determine the rate of oxygen 


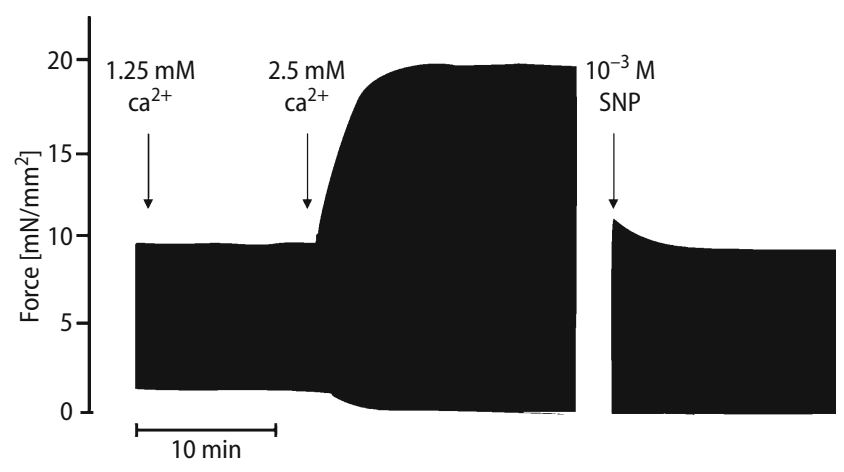

Fig. 1 Original registration of a representative experimental chart. Duplication of calcium from 1.25 to $2.5 \mathrm{mM}$ increased force by $100 \%$. Treatment with sodium nitroprusside decreased maximal force by $30 \%$

consumption of the muscle $\left(\mathrm{mVO}_{2}\right)$. Economy was calculated at each concentration of SNP and cGMP as the ratio of FTI to oxygen consumption.

\section{Statistics}

All results are reported as means \pm SD unless otherwise noted. Comparisons between NO treated and control muscles were performed by unpaired $t$ test or one-way ANOVA with a Tukey adjustment for multiple comparisons. A $P$ value $<0.05$ was considered significant for all tests.

\section{Results}

Dose-response experiments in 8 isometrically contracting papillary muscles from different animals were performed at $10^{-5}, 10^{-4}$, and $10^{-3} \mathrm{M}$ SNP. Active tension and FTI both decreased continuously with maximum depressions of $29 \pm 3 \%$ and $36 \pm 3 \%$ respectively at $10^{-3} \mathrm{M}$ SNP $(P<0.01)$ compared to control conditions at $2.5 \mathrm{mM}$ free calcium (Fig. 1) while diastolic tension remained unchanged. Consistent with previous experiments [27] SNP significantly decreased the time from peak twitch tension to $90 \%$ relaxation (RT90) by $20 \pm 5 \%(P<0.01)$. In addition, maximal relaxation velocity $(-\mathrm{d} T / \mathrm{d} t)$ increased by $20 \pm 7 \%(P<0.05)$. Time to peak tension (TTPT) and maximal velocity of force rise $(+\mathrm{d} T / \mathrm{d} t)$ were not found to be significantly altered (Fig. 2).

The free calcium concentration of the KrebsRinger solution was halved from 2.5 to $1.25 \mathrm{mmol} / \mathrm{l}$ to compare the observed negative inotropic effects of SNP. This intervention resulted in a $50 \pm 3 \%$ decrease in active force $(P<0.01)$ and a $37 \pm 6 \%$ decrease in FTI $(P<0.01)$ (Fig. 1). Time to peak tension, $+\mathrm{d} T / \mathrm{d} t$ and relaxation parameters were not affected (Fig. 2).

Muscle preparations showed a concentration dependent decrease in oxygen consumption with maximal reduction of $55 \pm 4 \%$ being reached at $10^{-3} \mathrm{M}$ SNP $(P<0.01)$. Halving the free calcium concentration resulted in a $40 \pm 6 \%$ decrease of oxygen consumption $(P<0.01)$ (Fig. 3). Though basal oxygen consumption under SNP and calcium did not differ $(P=\mathrm{NS})$.

Economy as a ratio of FTI to oxygen consumption increased under rising SNP concentrations up to $140 \pm 9 \%\left(\mathrm{SNP} 10^{-3} \mathrm{M} ; \quad P<0.01\right)$. However, the change in free calcium concentration did not show a significant difference in economy $(P=$ NS) (Fig. 4).

To investigate the possible role of increased intracellular cGMP levels through SNP, mechanical parameters and oxygen consumption were measured in another eight papillary muscle preparations.

Increasing concentrations of 8-bromo cGMP $\left(10^{-6}\right.$, $10^{-5}$ and $10^{-4} \mathrm{M}$ ) were added to the Krebs-Ringer solution. Twitch force and FTI decreased continuously with increasing cGMP concentrations. At $10^{-4} \mathrm{M} \mathrm{8-}$ bromo cGMP twitch force and FTI reached were mini-
Fig. 2 Representative twitches of right ventricular papillary muscles. Records show twitches at 1.25 and $2.5 \mathrm{mmol} / \mathrm{l} \mathrm{calcium}$ and $10^{-3} \mathrm{~mol} / / \mathrm{l}$ sodium nitroprusside (SNP). Halving the calcium concentration decreased force by $50 \%$. Other mechanical parameters were not effected. Treatment with SNP reduced maximal force by $30 \%$ and accelerated muscle relaxation
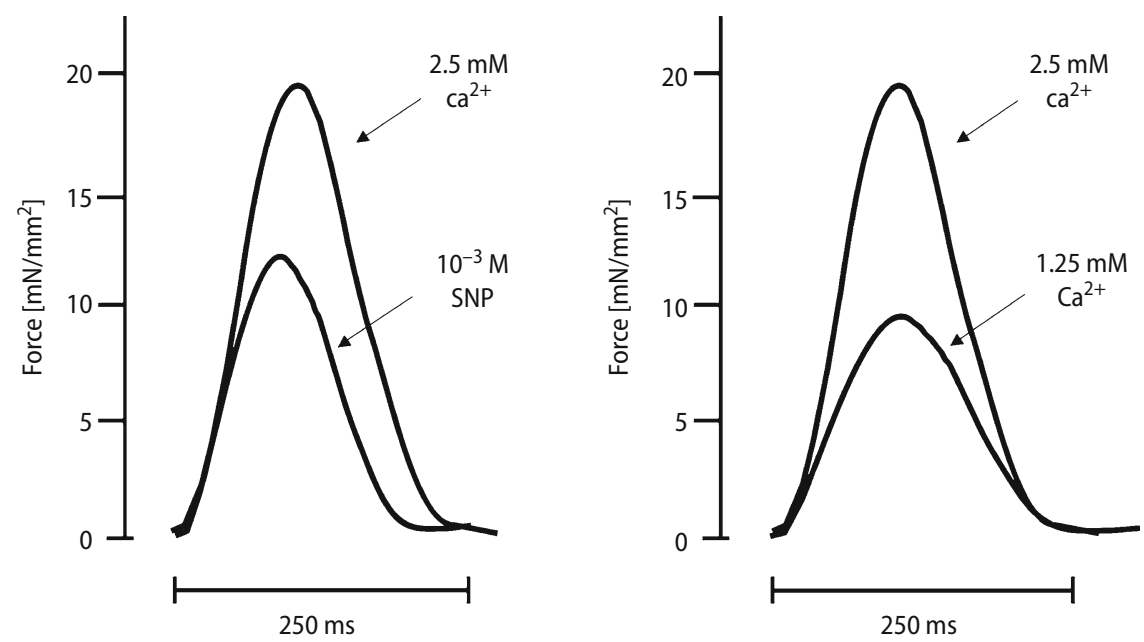


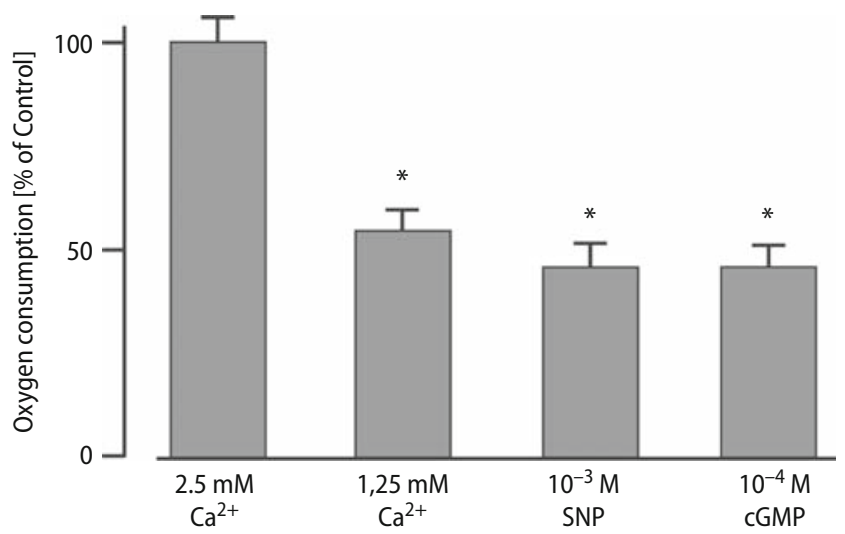

Fig. 3 Oxygen consumption normalized to $2.5 \mathrm{mmol} / /$ calcium as control. SNP, sodium nitropsusside; CGMP, cyclic guanosine monophosphate; *Statistically significant decrease in oxygen consumption

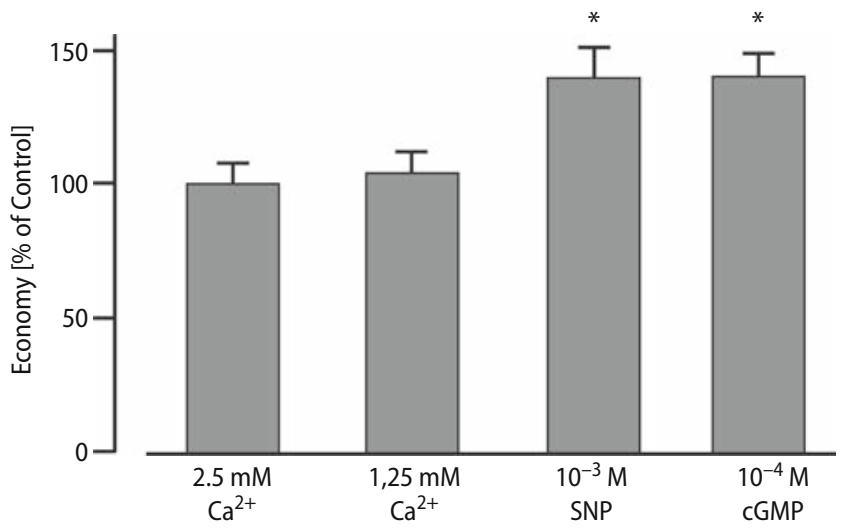

Fig. 4 Economy normalized to $2.5 \mathrm{mmol} / \mathrm{l}$ calcium as control. SNP, sodium nitroprusside, cGMP, cyclic guanosine monophosphate; *Statistically significant increase of economy

mal with reduction by $28 \pm 6 \%$ and $37 \pm 8 \%$ respectively (both $P<0.01$ ). Consistent with SNP experiments RT 90 was reduced by $19 \pm 4 \%$ and $-\mathrm{d} T / \mathrm{d} t$ increased by $26 \pm 7 \%$ (both $P<0.05$ ). TTPT and $+\mathrm{d} T / \mathrm{d} t$ were not affected. Halving of free calcium in the Krebs-Ringer solution showed similar results as described above (twitch force $-47 \pm 4 \%$, FTI $-42 \pm 6 \%$, no change in TTPT and relaxation parameters).

Oxygen consumption of cGMP treated muscle preparations decreased by $56 \pm 3 \% \quad(P<0.005)$ whereas the halving of calcium resulted in a $43 \pm 5 \%$ reduction $(P<0.005)$ (Fig. 3$)$. Therefore, the economy for cGMP treated muscles increased by $40 \pm 8 \%$ $(P<0.01)$ while the change in calcium concentration had no influence on economy $(P=$ NS) (Fig. 4$)$.

\section{Discussion}

In the present study SNP had a negative inotropic effect in isolated papillary muscles. These results are consistent with studies done in guinea pigs [2], cats $[22,23]$ and clinical studies with intracoronary infusion of SNP in humans [27]. The additionally described shortening of contraction time and the acceleration of relaxation could also be reproduced [7, 27]. However, some authors [2] observed no significant changes of the relaxation parameters or contraction time in guinea pig hearts. Species and tissue differences could be responsible for these differences.

The negative inotropic effect of SNP was associated with a disproportionate decrease in oxygen consumption as compared to the proportional decrease in active force and oxygen consumption induced by reducing the $\mathrm{Ca}^{2+}$ concentration from 2.5 to $1.25 \mathrm{mM}$. As a consequence contraction economy increased with SNP whereas halving the calcium concentration had no influence on myocardial energetics.

The participation of NO in the ischemic preconditioning cell-survival program is widely discussed in the literature. Previous studies [17, 18, 40] indicated that endothelium-derived NO is an important regulator of tissue oxygen consumption in myocardium in vivo and vitro. The mechanisms underlying cytoprotection involve the modulation of mitochondrial function such as reversal inhibition of cytochrome $c$ oxidase and a reduction of mitochondrial enzyme activities including aconitase in the Krebs cycle and complex I and II of the mitochondrial electron transport chain.

Peroxinitrate, formed by the interaction of NO with superoxide, also promotes a suppression of respiration [43]. However, the inhibition of cellular respiration by peroxinitrate is not reversible. Thus, it is unlikely to act as a potent physiological regulator for tissue oxygen consumption.

Additionally, Rickover et al. [34] described a SNP triggered activation of the sarcoplasmic calciumATPase with increased $\mathrm{Ca}^{2+}$ uptake into the sarcoplasmic reticulum and thus prevention of cytosolic $\mathrm{Ca}^{2+}$ overload in rat cardiomyocytes. The overproportional decrease of oxygen consumption and increase in contraction economy after SNP treatment observed in our study may result from effects on calcium cycling and be part of the beneficial effects of NO during ischemia/reperfusion when oxygen is limiting and tissue becomes acidotic and may enhance ischemic tolerance during preconditioning.

Moreover, NO has been shown to control substrate utilization of myocytes [33,45]. Lack of NO causes preferential utilization of carbohydrates by myocardium. This deficit may be important especially in heart failure and diabetes when NO production by blood vessels is reduced or abolished. Recchia [32] hypothesized that prevalent carbohydrate utilization might be advantageous for the heart because the ATP yield from carbohydrate oxidation is greater for a 
given rate of oxygen consumption, due to the higher ATP/oxygen ratio compared to that of free fatty acid oxidation. Switching from free fatty acid to lactate can result in a reduction of around $10 \%$ of oxygen consumption [30]. However, healthy hearts in the fasting state consume primarily fatty acids, because this is their optimal substrate. The shift to prevalent carbohydrate utilization by the failing heart likely represents an adaptive response to face profoundly altered mechanics and energy turnover e.g. increased basal oxygen consumption and reduced efficiency, even if it could be disadvantageous in the long-term.

To further investigate the role of NO on subcellular mechanisms in myocytes, the membrane permeable cGMP-analogue 8-bromo cGMP was used. Through experimentation it was determined that 8-bromo cGMP produced similar results to SNP at only one tenth of the SNP concentration. These findings suggest that the effects of NO on myocytes are primarily mediated by cGMP and consistent to recent studies [16].

Guanylate cyclase is stimulated by extracellular NO and synthesizes cGMP from guanosine triphosphate (GTP). Within the myocardial cells cGMP and cyclic adenosine monophosphate (cAMP) are antagonists. Previous studies described dose dependent effects on contractile function of cGMP or rather NO $[15,31]$. On one hand very low NO concentrations increase intracellular cAMP levels by activation of adenylyl cyclases directly [14] and by a cGMP-mediated inhibition of phosphodiesterase $[29,35]$ with a consequently diminished breakdown of cAMP. This leads to phosphorylation and thus activation of the L-type calcium channel and other key proteins in calcium cycling $[38,44]$. Therefore, calcium influx and calcium transients are increased in myocytes resulting in an increase in contractile function but also myocardial oxygen consumption. Moreover, positive inotropic effects of low-dose NO are possible by increasing contractile calcium responsiveness [10]. On the other hand high NO concentrations activate a cGMP dependent cAMP phosphodiesterase with consequent reduction in cAMP concentrations [4,35]. Additionally, the cAMP phosphorylated L-type calcium channel is dephosphorylated by cGMP dependent phosphatase(s) [38] and troponin I and phospholamban are phosphorylated $[13,16]$. Phosphorylation of troponin I reduces the calcium sensitivity of the thin filament by a decrease of the affinity of troponin $\mathrm{C}$ to calcium and amplifies the loss in tension [12, 16, $25]$. Evidence that high cGMP concentrations cause a negative inotropic effect was shown by extracelluar application of acetylcholine [6]. In other experiments with similar results a cGMP-analogue was used [35]. Moreover, phosphorylated troponin I prevents calcium-independent diastolic cross-bridge cycling [26]. Phosphorylation of phospholamban activates the sarcoplasmic calcium-ATPase and thereby accelerates calcium elimination out of the cytosol [28]. A further decrease in systolic and diastolic force and additional shortening of contraction time would result. The described effects are in agreement with our findings of a shortened relaxation time and an increase in relaxation velocity. However, consistent with previous experiments [11] there was no significant change in diastolic force generation assuming that diastolic stiffness is negligible in nonfailing rabbit myocardium in contrast to patients with dilated cardiomyopathy or aortic stenosis.

Thus, the negative inotropic effect of SNP observed in our experiments may be caused by dephosphorylation of the L-type calcium channel, a decreased cAMP concentration in the cell, an accelerated calcium uptake in the sarcoplasmic reticulum or a shift in thin filament calcium sensitivity.

The mechanism behind the improvement of the contraction economy is not clear. Economy improvement may be due to the increases in economy of ATP synthesis or a reduction of ATP usage per unit of developed tension. Animal models have shown that under special experimental conditions NO reduces the ATP synthesis in mitochondria [3]. However, basal oxygen consumption under $\mathrm{NO}$ and control conditions did not differ in our experiments, suggesting the economy of ATP synthesis remained unchanged (data not shown). Due to technical reasons high solution oxygen partial pressures are needed in the diffusion method. Therefore, effects of super-physiological oxygen partial pressures on mitochondria NO interactions and NO metabolism can not be excluded and may have an impact on the observed results.

A reduction of ATP usage per unit of developed tension may be a result of changes in excitationcontracting coupling or myofibrillar performance. Both require energy during the contraction-relaxation cycle [19]. Given that excitation-contracting coupling requires $15-20 \%$ of the total ATP used [8], it is unlikely that the demonstrated improvement in contraction economy is based on effects on excitationcontracting coupling alone. Moreover, decreased calcium sensitivity by phosphorylation of troponin I may rather increase energy consumption for calcium cycling [12, 25]. Therefore, a major reduction of ATP usage seems to be caused by improved economy at the level of myofibrillar proteins. The underlying mechanism may be an increase in the FTI of a single cross-bridge through a lengthened thin filament attachment time to myosin. A corresponding change of cross-bridge economy was demonstrated with some calcium sensitizers [9] as well as in hypertrophic and insufficient myocardium [8]. This effect caused by NO is most likely responsible for the improvement in contraction economy. 
The more pronounced decrease in oxygen consumption relative to FTI and therefore the increase in economy of isolated papillary muscle preparations after SNP treatment may be part of the improvement observed in nitrate treated patients with coronary heart disease.

\section{References}

1. Balligand JL, Ungureanu D, Kelly RA, Kobzik L, Pimental D, Michel T, Smith TW (1993) Abnormal contractile function due to induction of nitric oxide synthesis in rat cardiac myocytes follows exposure to activated macrophage-conditioned medium. J Clin Invest 91:2314-2319

2. Brady AJ, Warren JB, Poole-Wilson PA, Williams TJ, Harding SE (1993) Nitric oxide attenuates cardiac myocyte contraction. Am J Physiol 265:H176-H182

3. Brown GC, Borutaite V (2007) Nitric oxide and mitochondrial respiration in the heart. Cardiovasc Res 75:283-290.

4. Fischmeister R, Hartzell HC (1981) Cyclic guanosine $3^{\prime}, 5^{\prime}$-monophosphate regulates the calcium current in single cells from frog ventricel. J Physiol 387:453-472.

5. Fort S, Lewis MJ, Shah AM (1993) The role of endocardial endothelium in the modulation of myocardial contraction in the isolated whole heart. Cardioscience 4:217-223.

6. George WJ, Polson JB, O’Toole AG, Goldberg ND (1970) Elevation of guanosine $3^{\prime}, 5^{\prime}$-cyclic phosphate in rat heart after perfusion with acetylcholine. Proc Natl Acad Sci USA 66:398403

7. Grocott-Mason R, Fort S, Lewis MJ, Shah AM (1994) Myocardial relaxant effect of exogenous nitric oxide in isolated ejecting hearts. Am J Physiol 266:H1699-H1705

8. Hasenfuss G, Mulieri LA, Leavitt BJ, Allen PD, Haeberle JR, Alpert NR (1992) Alteration of contractile function and excitation-contraction coupling in dilated cardiomyopathy. Circ Res 70:1225-1232

9. Hasenfuss G, Pieske B, Kretschmann B, Holubarsch C, Alpert NR, Just H (1995) Effects of calcium sensitizers on intracellular calcium handling and myocardial energetics. J Cardiovasc Pharmacol 26 Suppl 1:S45-S51

10. Heusch G, Post H, Michel MC, Kelm M, Schulz R (2000) Endogenous nitric oxide and myocardial adaptation to ischemia. Circ Res 87:146-152

11. Holmes JW, Hünlich M, Hasenfuss G (2002) Energetics of the Frank-Starling effect in rabbit myocardium: economy and efficiency depend on muscle length. Am J Physiol Heart Circ Physiol 283:H324-H330
12. Hünlich M, Begin KJ, Gorga JA, Fishbaugher DE, LeWinter MM, VanBuren P (2005) Protein kinase A mediated modulation of acto-myosin kinetics. J Mol Cell Cardiol 38:119-125

13. Karczewski P, Hendrischke T, Wolf WP, Morano I, Bartel S, Schrader J (1998) Phosphorylation of phospholamban correlates with relaxation of coronary artery induced by nitric oxide, adenosine, and prostacyclin in the pig. J Cell Biochem 70:49-59

14. Kelly RA, Ballingand JL Smith TW (1996) Nitric oxide and cardiac function. Circ Res 79:363-380

15. Kojda G, Kottenberg K, Nix P, Schlüter KD, Piper HM, Noack E (1996) Low increase in cGMP induced by organic nitrates and nitrovasodilators improves contractile response of rat ventricular myocytes. Circ Res 78:91-101

16. Layland J, Li JM, Shah AM (2002) Role of cyclic GMP-dependent protein kinase in the contractile response to exogenous nitric oxide in isolated cardiac myocytes. J Physiol 540.2:457-467

17. Li W, Jue T, Edwards J, Wang X, Hintze TH (2004) Changes in NO bioavailability regulate cardiac $\mathrm{O}_{2}$ consumption: control by intramitochondrial SOD2 and intracellular myoglobin. Am J Physiol Heart Circ Physiol 286:H47H54

18. Loke KE, McConnell PI, Tuzman JM, Shesely EG, Smith CJ, Stackpole CJ, Thompson CI, Kaley G, Wolin MS, Hinzte TH (1999) Endogenous endothelial nitric oxide synthase-derived nitric oxide is a physiological regulator of myocardial oxygen consumption. Circ Res 84:840-845

19. Maack C, O'Rourke B (2007) Excitation-contraction coupling and mitochondrial energetics. Basic Res Cardiol 102:369-392

20. Meulemans AL, Sipido KR, Sys SU, Brutsaert DL (1988) Atriopeptin III induces early relaxation of isolated mammalian papillary muscle. Circ Res 62:1171-1174

21. Meyer M, Keweloh B, Güth K, Holmes JW, Pieske B, Lehnart SE, Just H, Hasenfuss G (1998) Frequency-dependence of myocardial energetics in failing human myocardium as quantified by a new method for the measurement of oxygen consumption in muscle strip preparations. J Mol Cell Cardiol 30:1459-1470
22. Mohan P, Brutsaert DL, Paulus WJ, Sys SU (1996) Myocardial contractile response to nitric oxide and cGMP. Circulation 93:1223-1229

23. Mohan P, Sys SU, Brutsaert DL (1995) Positive inotropic effect of nitric oxide in myocardium. Int J Cardiol 50:233237

24. Mulieri LA, Hasenfuss G, Ittleman F, Blanchard EM, Alpert NR (1989) Protection of human left ventricular myocardium from cutting injury with 2,3butanedione monoxime. Circ Res 65:1441-1449

25. Noguchi T, Hünlich M, Camp PC, Begin $\mathrm{KJ}$, El-Zaru $\mathrm{M}$, Patten $\mathrm{R}$, Leavitt $\mathrm{BJ}$, Ittleman FP, Alpert NR, LeWinter MM, VanBuren P (2004) Thin-filamentbased modulation of contractile performance in human heart failure. Circulation 110:982-987

26. Paulus WJ, Bronzwaer JGF (2004) Nitric oxide's role in the heart: control of beating or breathing. Am J Physiol Heart Circ Physiol 287:H8-H13

27. Paulus WJ, Vantrimpont PJ, Shah AM (1994) Acute effects of nitric oxide on left ventricular relaxation and diastolic distensibility in humans: assessment by bicoronary sodium nitroprusside infusion. Circulation 89:2070-2078

28. Periasamy M, Bhupathy P, Babu GJ (2008) Regulation of sarcoplasmic reticulum $\mathrm{Ca}^{2+}$ ATPase pump expression and its relevance to cardiac muscle physiology and pathology. Cardiovasc Res 77:265-273

29. Prekel B, Kojda G, Schlack W, Ebel D, Kottenberg K, Noack E, Thämer V (1997) Inotropic effects of glyceryl trinitrate and spontaneous NO donors in the dog heart. Circulation 96:24932495

30. Randel PJ, Englasnd PJ, Denton RM (1970) Control of the tricarboxylate cycle and its interactions with glycolysis during acetate utilization in rat heart. Biochem J 117:677-695

31. Rassaf T, Poll LW, Brouzos P, Lauer T, Totzeck M, Kleinbongard P, Gharini P, Andersen K, Schulz R, Heusch G, Mödder U, Kelm M (2006) Positive effects of nitric oxide on left ventricular function in humans. Eur Heart J 27:1699-1705

32. Recchia FA (2002) Role of nitric oxide in the regulation of substrate metabolism in heart failure. Heart Fail Rev 7:141-148 
33. Recchia FA, McConnell PI, Loke KE, Xu X, Ochoa M, Hintze TH (1999) Nitric oxide controls cardiac substrate utilization in the conscious dog. Cardiovasc Res 44:325-332

34. Rickover O, Zinman T, Kaplan D, Shainberg A (2008) Exogenous nitric oxide triggers classic ischemic preconditioning by preventing intracellular $\mathrm{Ca}^{2+}$ overload in cardiomyocytes. Cell Calcium 43:324-333

35. Shah AM, Lewis MJ, Henderson AH (1991) Effects of 8-bromo-cyclic GMP on contraction and on inotropic response of ferret cardiac muscle. J Mol Cell Cardiol 23:55-64

36. Shah AM, MacCarthy PA (2000) Paracrine and autocrine effects of nitric oxide on myocardial function. Pharmacol Ther 86:49-86

37. Shah AM, Spurgeon HA, Sollott SJ, Talo A, Lakatta EG (1994) 8-bromocGMP reduces the myofilament response to $\mathrm{Ca}^{2+}$ in intact cardiac myocytes. Circ Res 74:970-978

38. Shen JB, Pappano AJ (2002) On the role of phosphatase in regulation of cardiac L-type calcium current by cyclic GMP. J Pharmacol Exp Ther 301:501-506
39. Shinke $\mathrm{T}$, Takaoka $\mathrm{H}$, Takeuchi $\mathrm{M}$, Hata K, Kawai H, Okubo H, Kijima Y, Murata T, Yokoyama M (2000) Nitric oxide spares myocardial oxygen consumption through attenuation of contractile response to beta-adrenergic stimulation in patients with idiopathic dilated cardiomyopathy. Circulation 101:1925-1930

40. Shiva S, Sack MN, Greer JJ, Duranski M, Ringwood LA, Burwell L, Wang X, MacArthur PH, Shoja A, Raghavachari N, Clavert JW, Brookes PS, Lefer DJ, Gladwin MT (2007) Nitrate augments tolerance to ischemia/reperfusion injury via the modulation of mitochondrial electron transfer. JEM 204:20892102

41. Smith JA, Shah AM, Fort S, Lewis MJ (1992) The influence of endocardial endothelium on myocardial contraction. Trends Pharmacol Sci 13:113-116

42. Smith JA, Shah AM, Lewis MJ (1991) Factors released from endocardium of the ferret and pig modulate myocardial contraction. J Physiol 439:1-14

43. Szabo C, Salzman AL (1995) Endogenous peroxynitrite is involved in the inhibition of mitochondrial respiration in immuno-stimulated J774.2 macrophages. Biochem Biophys Res Commun 209:739-743
44. Tang T, Lai NC, Roth DM, Drumm J, Guo T, Lee KW, Han PL, Dalton N, Gao MH (2006) Adenylyl cyclase type V deletion increases basal left ventricular function and reduces left ventricular contractile responsiveness to $\beta$-adrenergic stimulation. Basic Res Cardiol 101:117-126

45. Trochu JN, Bouhour JB, Kaley G, Hintze TH (2000) Role of endotheliumderived nitric oxide in the regulation of cardiac oxygen metabolism: implications in health and disease. Circ Res 87:1108-1117

46. Ungureanu-Longrois D, Balligand JL, Okada I, Simmons WW, Kobzik L, Lowenstein CJ, Kunkel SL, Michel T, Kelly RA, Smith TW (1995) Contractile responsiveness of ventricular myocytes to isoproterenol is regulated by induction of nitric oxide synthase activity in cardiac microvascular endothelial cells in heterotypic primary culture. Circ Res 77:486-493

47. Wittstein IS, Kass DA, Pak PH, Maughan WL, Fetics B, Hare JM (2001) Cardiac nitric oxide production due to angiotensin-converting enzyme inhibition decreases beta-adrenergic myocardial contractility in patients with dilated cardiomyopathy. J Am Coll Cardiol 38:429-435 